\title{
Austeridade Fiscal, Impactos Regionais e Ganhos de Produtividade: Projeções para a Economia Brasileira
}

\author{
Guilherme Silva Cardoso $^{1}$ | Thiago Cavalcante Simonato ${ }^{2}$ | Débora Freire Cardoso ${ }^{3}$ (D) | \\ Edson Paulo Domingues ${ }^{4}$ \\ ${ }^{1}$ Universidade Federal de Minas Gerais. E-mail: scardoso.guilherme@gmail.com \\ ${ }^{2}$ Universidade Federal de Minas Gerais. E-mail: thiagocavalcantesimonato@hotmail.com \\ ${ }^{3}$ Universidade Federal de Minas Gerais. E-mail: dfreirecardoso@gmail.com \\ ${ }^{4}$ Universidade Federal de Minas Gerais. E-mail: epdomin@cedeplar.ufmg.br
}

\begin{abstract}
RESUMO
Este artigo tem como objetivo projetar qual deve ser a variação da produtividade do trabalho, em resposta à atual agenda de reformas estruturais no Brasil, para compensar os impactos contracionistas da austeridade fiscal, considerando a heterogeneidade regional do país. Para isso, utiliza-se um modelo de equilíbrio geral inter-regional dinâmico para 27 Unidades da Federação brasileiras, permitindo uma análise bottom-up. Os principais resultados mostram que o aumento da produtividade do trabalho necessário para atenuar os efeitos contracionistas da consolidação fiscal varia consideravelmente entre as Unidades da Federação, sendo relativamente mais oneroso para a região Nordeste. Os resultados macroeconômicos também seguem o mesmo padrão de heterogeneidade regional. O aumento da produtividade do trabalho nos estados mais afetados pelos impactos contracionistas da austeridade é pouco factível devido à baixa perspectiva de crescimento do consumo das famílias, do investimento e ao alto desemprego em economias cuja composição setorial é pouco beneficiada com a agenda de austeridade e reformas.
\end{abstract}

\section{PALAVRAS-CHAVE}

Austeridade fiscal, Economia regional, Equilíbrio geral computável, Produtividade do trabalho, Reformas estruturais

Fiscal Austerity, Regional Impacts and Productivity Gains: Projections for the Brazilian Economy

\begin{abstract}
This article aims to project the variation in labor productivity in response to structural reforms in Brazil necessary to offset the contractionary impacts of this agenda, considering regional heterogeneities. For this, a dynamic interregional general equilibrium model is used for 27 Brazilian federative units, allowing a bottom-up analysis. The main results show that the increase in labor productivity necessary to mitigate the contractionary effects of fiscal consolidation varies considerably between the Federation Units, relatively more onerous to the Northeast region. Macroeconomic results also follow the same pattern of regional heterogeneity. The increase in labor productivity in the states most affected by the contractionary impacts of austerity is hardly feasible due to the low prospect of household consumption, falling investment and high unemployment in a sectoral composition that has little benefit from the austerity and reforms agenda.
\end{abstract}

\section{KEYWORDS}

Fiscal austerity, Regional economics, Computable general equilibrium, Labor productivity, Structural reforms

\author{
CLASSIFICAÇÃO JEL \\ R11, R38, C68
}




\section{Introdução}

No atual debate público brasileiro, registra-se, em paralelo às medidas austeras do governo Federal pelo lado dos gastos e à tentativa de adoção de consolidações fiscais nas Unidades da Federação via Plano de Recuperação Fiscal proposto pelo Governo Federal, a discussão a respeito da necessidade de aprovação de reformas estruturais, como as de liberalização do mercado de trabalho, elevação do tempo médio de contribuição previdenciária do trabalhador e modificação da estrutura tributária.

Conforme o extenso compilado de teorias e evidências empíricas apresentado em Alesina et al. (2020), Alesina et al. (2018) as contrações fiscais podem alcançar resultados expansionistas. Para países da OCDE, Bouis et al. (2012), Alesina et al. (2018) e Annicchiarico et al. (2013) constatam, em maior ou menor autonomia e tempo de maturação, o logro de consolidações fiscais em períodos de estagnação econômica. Essa conclusão, apoiada principalmente no papel das expectativas, se contrapõe ao argumento Keynesiano de que consolidações fiscais exerceriam efeito contracionista na demanda agregada no curto prazo. Assim, austeridade expansionista (ou contração fiscal expansionista) pode ser definida como a correlação positiva entre o ajustamento fiscal, seja via corte de gastos públicos ou aumento da tributação, e o consumo e investimento privado.

Um dos contextos que permitiria resultado expansionista decorrente de consolidações fiscais segundo essa literatura se deve às chamadas políticas de acompanhamento, que variam desde a adoção concomitante de política monetária contracionista e da liberalização do mercado de capitais, conforme a análise pioneira de Giavazzi e Pagano (1990), às reformas estruturais no mercado de trabalho e dos setores produtivos (mercado de produtos).

Para o Brasil, os impactos da austeridade fiscal ainda são incertos, seja no nível macroeconômico e setorial ou no espectro social, no bem-estar das famílias e na distribuição de renda. Embora a implementação da Emenda Constitucional (EC) 95/2016 ${ }^{1}$ tivesse o objetivo de ancorar as expectativas dos agentes econômicos, limitando o crescimento do gasto público em um contexto de insolvência fiscal, conforme salientam Salto e Barros (2018), já se discute a possibilidade da flexibilização do teto, dada a persistência da elevada capacidade ociosa e desemprego, bem como a falta de investimento público em setores como saúde, educação e infraestrutura (Giambiagi e Horta, 2019).

É amplo e antigo o histórico de reformas no Estado brasileiro (Costa, 2008). Essas reformas, no entanto, diferem-se consideravelmente entre si. Se nos anos 1950 e 1960

\footnotetext{
${ }^{1}$ A Emenda Constitucional no 95 (EC 95), de 15 de dezembro de 2016, estabeleceu o Novo Regime Fiscal (NRF) no âmbito do Orçamento Fiscal e da Seguridade Social da União, o qual vigorará por vinte exercícios financeiros. O NRF fixa limites individualizados para o Poder Executivo, para os órgãos dos Demais Poderes, Ministério Público da União - MPU e Defensoria Pública da União (DPU), para as despesas primárias dos órgãos integrantes daqueles orçamentos e estabelece, nos termos do $\S 1^{\circ}$ do art. 107, o método para sua apuração (Brasil, 2018).
} 
estiveram marcadas pelo desenvolvimentismo - a partir dos anos 1980 e, principalmente, 1990, sofreu influência das políticas de liberalização da economia (Cardoso, 2022). Atualmente, as reformas são constantemente trazidas ao debate público como agenda imprescindível à retomada do crescimento brasileiro, justificadas pelo fato de agirem no sentido de liberalizar e facilitar a ação do setor privado, de forma a atenuar o eventual impacto negativo de curto prazo na atividade econômica decorrente da consolidação fiscal, como argumenta parte da literatura.

Segundo Anderson et al. (2014), as reformas afetam positivamente a produtividade do trabalho e o nível de emprego por meio da liberalização do mercado de trabalho e de produtos. De acordo com Bouis et al. (2012), flexibilizações nas legislações trabalhistas, por exemplo, diminuem as restrições de contratação e demissão de funcionários que, por sua vez, podem elevar a produtividade do trabalho, apesar da redução do poder de barganha do trabalhador e aumento, muita das vezes, da precarização e custos sociais (Rubery e Piasna, 2016); (Shin, 2013). Até mesmo reformas previdenciárias que promovam elevação da idade de aposentadoria e neutralidade atuarial ${ }^{2}$, elevam a taxa de participação da força de trabalho para um novo equilíbrio em cerca de 10 anos segundo estimativas de Bassanini e Duval (2006) e Bassanini e Duval (2009), que, sob ponto de vista do trabalhador, também são passíveis de efeitos adversos (Boeri et al., 2002); (Kodar, 2004).

Argumentos menos otimistas com relação ao logro das reformas estruturais podem ser encontrados em Rodrik (2017), que ressalta o fato de apesar do objetivo de elevar o produto potencial da economia a longo prazo, realocando fatores para setores mais produtivos, seus impactos são muitas das vezes sobrestimados. Para Bardaka et al. (2021), ao menos que as reformas estruturais sejam cuidadosamente planejadas, essas políticas podem falhar mesmo a longo prazo, tendo em vista a má realocação de recursos para setores improdutivos (baixo valor agregado).

Uma lacuna nessas discussões sobre efeitos da austeridade e de reformas estruturais, no entanto, se encontra na escassez de análises regionais dos impactos dessas medidas. A análise regional é importante por captar as heterogeneidades comuns ao espaço, em especial no Brasil, um país continental e de grandes desigualdades regionais, sociais, econômicas e estruturais. Essas desigualdades fazem com que a importância do gasto público para as economias e bem-estar das famílias e a própria dinâmica e estrutura produtiva varie muito entre as regiões.

Para diferentes países, Caraveli e Tsionas (2012); Beatty e Fothergill (2013); Cabrera et al. (2015); Pearce (2013); Greer Murphy (2017); Green e Lavery (2015); e Tupy e Toyoshima (2013) destacam o papel central da atuação do setor público e das transferências de renda do governo para as famílias no que concerne às desigualda-

\footnotetext{
${ }^{2}$ Modelo previdenciário em que se é indiferente entre as situações em que as pessoas tendem a reivindicar benefícios antes da idade de aposentadoria completa (FRA), na FRA ou após a FRA, porque, em média, o aumento que as pessoas recebem por reivindicar mais tarde é aproximadamente compensado pelo fato de receberem menos pagamentos até o final da vida.
} 
des inter-regionais de renda. Isso ocorre devido à menor articulação e capacidade de geração de renda da estrutura produtiva de algumas regiões em cada país. A maior dependência dos municípios menores e mais pobres da ação setor público, seja via direta, na administração e provisão de serviços, seja indireta, via transferências de renda, é um fato estilizado na literatura de economia regional, são as chamadas "economias sem produção”.

No que concerne às consolidações fiscais e seus efeitos regionais, Cardoso et al. (2019) avaliam os impactos diretos e indiretos de uma agenda de austeridade fiscal do governo brasileiro nas desigualdades regionais e setoriais do país. Os autores projetam cenários austeros para o crescimento dos gastos públicos na economia brasileira, sem e com a recuperação do investimento privado (i.e, considerando a hipótese de austeridade fiscal expansionista) e concluem que, mesmo que a recuperação do investimento privado fosse suficiente para contrabalançar os impactos negativos do corte de gastos no crescimento econômico, haveria piora nos indicadores macroeconômicos e de desigualdade entre municípios e estados da região Norte e Nordeste, relativamente ao restante do Brasil.

Considerando a literatura favorável ao efeito positivo das reformas estruturais, no tocante à produtividade do trabalho, e aquela que discute o papel do Governo nas desigualdades regionais, o presente artigo propõe a mensuração da elevação da produtividade do trabalho necessária para compensar o efeito da contração do gasto público no PIB, oriunda do aprofundamento e da extensão regional da agenda de austeridade fiscal no Brasil nos próximos anos. Ainda, considerando a estrutura regional brasileira, busca-se avaliar a heterogeneidade dos eventuais ganhos de produtividade nas Unidades da Federação (UFs) do país. Para isso, utiliza-se um modelo de equilíbrio geral computável (EGC) com dinâmica recursiva calibrado para as 27 UFs brasileiras. O modelo é baseado em dados de 2015 publicados pelo Sistema de Contas Nacionais (SCN) do Brasil (IBGE, 2019) e permite uma análise bottom-up do nível estadual ao nacional.

O presente artigo inova ao investigar qual deve ser o ganho de produtividade regional para compensar os efeitos contracionistas da austeridade fiscal no Brasil, por meio de modelo de EGC. Seus resultados estão de acordo com a literatura apresentada quanto aos aspectos da convergência regional da estrutura produtiva brasileira, bem como das desigualdades regionais. Apesar de não considerar a influência da pandemia provocada pelo COVID-19, os temas aqui trazidos estão intimamente ligados a tal problemática, tanto no enfrentamento quanto à superação da crise multissistêmica provocada pelo vírus.

Além da presente introdução, o trabalho está dividido em mais quatro seções: a primeira, apresenta os principais estudos relacionados às reformas estruturais e seus desdobramentos acerca da produtividade do trabalho e desigualdades regionais; em seguida, descreve-se a metodologia, que apresenta a estrutura do modelo utilizado no presente estudo, a estratégia de simulação e a base de dados do modelo; os resultados 
são apresentados na seção 4. Por fim, tecem-se as considerações finais.

\section{Reformas estruturais, produtividade do trabalho e desi- gualdades regionais}

Os programas de austeridade costumam ser acompanhados de uma ambiciosa agenda de reformas estruturais do tipo "big bang": fazer o maior número possivel de mudanças, o mais rápido possivel (Bardaka et al., 2021). Elas têm o objetivo de aumentar a eficiência com que trabalho e capital são alocados na economia, garantindo que esses recursos cheguem aonde sua contribuição para a renda nacional for maior. Se bem-sucedidas, essas mudanças promovem produtividade, investimento e crescimento. As reformas estruturais fazem frequentemente parte da condicionalidade que acompanha assistências financeiras a países endividados (Rodrik, 2017).

Mais diversificadas para o mercado de trabalho, as reformas estruturais se apresentam via redução de barreiras à entrada de profissionais, redução da legislação de proteção e dos benefícios de desemprego, elevação da idade de aposentadoria, redução do custo de oportunidade para a manutenção da força de trabalho em idade de aposentadoria, elevação do suporte infantil (creches e maternais) e implementação de programas ativos no mercado de trabalho que visem facilitar a procura por postos de trabalho. Para o mercado de produtos, as reformas objetivam reduzir regulações que prejudiquem a competitividade do mercado, reduzindo barreiras legais e administrativas ao empreendedorismo, bem como ao comércio e investimento internacional (Anderson et al., 2014).

Nicoletti e Scarpetta (2005) investigam a estratégia adotada pela maioria dos países da OCDE que implementaram amplas reformas regulatórias nas décadas de 1980 e 1990, com o objetivo de promover o empreendedorismo e a concorrência no mercado de produtos. Segundo os autores, privatização; liberalização de entrada e preços em mercados domésticos potencialmente competitivos; regulação pró-competitiva de mercados de monopólio natural (por exemplo, regulando o acesso a redes); e maior liberalização comércio internacional e investimento estrangeiro direto foram de fato as principais medidas adotadas. Os resultados econométricos sugerem que reformas pró-competitivas tendem a aumentar o investimento e a produtividade multifatorial e, por ambos os canais, podem levar a um crescimento maior do PIB per capita.

Para a economia italiana, no período recente de Crise da Dívida, Annicchiarico et al. (2013) consideram que as reformas estruturais são capazes de trazer ganhos consideráveis na produção, consumo, emprego e nos ativos externos líquidos principalmente devido às reformas no mercado de trabalho. Ao contrário da ordem de causalidade usualmente retratada na literatura, os autores argumentam que se deve aos efeitos recessivos da austeridade fiscal a mitigação de parte dos efeitos positivos das intervenções estruturais, especialmente durante as fases iniciais do processo de reforma. 
Argumentos favoráveis ao logro das reformas estruturais em situações de consolidações fiscais também são defendidos em Bouis et al. (2012) e Alesina et al. (2018). Para 16 países da OCDE, no período de 1978-2014, Alesina et al. (2018) concluem que consolidações fiscais via corte de gastos são menos custosas do que quando executadas por meio do aumento da tributação graças ao papel da confiança e das políticas de acompanhamento. Com base na análise empírica de 30 anos de reformas estruturais em todas os países da OCDE, Bouis et al. (2012) indicam que os benefícios das reformas estruturais normalmente levam tempo para se materializarem completamente. Quando significativos a curto prazo, os efeitos das reformas raramente envolvem perdas econômicas agregadas, mas, pelo contrário, muitas vezes impactam positivamente no produto. Os autores afirmam não haver necessidade de substancial flexibilização da política macroeconômica para o logro de curto prazo das reformas.

Opositor à manutenção da prática de medidas de austeridade fiscal na recente crise da dívida grega, Rodrik (2017) destaca que, embora o objetivo principal seja realocar fatores para setores mais produtivos, os impactos das reformas estruturais sobre a produtividade agregada são sobrestimados quando se leva em conta a lenta convergência do produto real para o produto potencial de longo prazo - aquele geralmente considerado na literatura. O autor considera, portanto, o fato de que as mudanças exigem anos para surtir efeito na economia e, devido ao lento processo de convergência, podem produzir "efeitos perversos".

Com base nos resultados de um estudo recente com países da OCDE, Bardaka et al. (2021) alertam que, a menos que cuidadosamente planejada como uma remoção seletiva e direcionada dos principais obstáculos que impedem o crescimento, a política orientada às reformas estruturais pode não funcionar mesmo no longo prazo. Segundo os autores, um ousado programa de liberalização em toda a economia, como complemento da austeridade, pode ainda direcionar recursos para setores improdutivos (baixo valor agregado) e os resultados alcançados podem ser o oposto do esperado com relação ao aumento da produtividade agregada.

Avaliações da relação entre reformas estruturais, produtividade do trabalho e desigualdades regionais também são escassas e carecem de consenso. Para a Colômbia, Eslava et al. (2004) investigam os efeitos das reformas do mercado de produtos, como a remoção das restrições às importações e do investimento estrangeiro direto, introduzidas na Colômbia no início dos anos 1990. Com base em dados longitudinais no nivel da empresa para o período de 1982-1998, eles encontraram evidências de que as reformas estão associadas a um aumento na produtividade geral, em grande parte impulsionado pela realocação de empresas de baixa e alta produtividade. Essas mudanças, no entanto, não afetaram o persistente histórico de desigualdade regional no país,conforme avaliam Fergusson et al. (2017). Nesse sentido, para a Índia, Unni et al. (2001) constatam que as reformas liberais na indústria e no comércio internacional ao longo das décadas de 1980 e 1990 beneficiaram apenas a região de Gujarat, que já era a mais industrializada do país antes das reformas, em termos de valor agregado, 
emprego, capital e produtividade. Os autores também observam uma piora geral pósreforma no setor informal em relação ao setor formal em todo o país.

Para nivel de entendimento da evolução recente da produtividade do trabalho no Brasil, em termos setorial e regional, bem como uma comparação internacional dos números da produtividade, apresenta-se, a seguir, as principais contribuições brasileiras ao tema. Silva et al. (2016) apresentam uma comparação internacional da evolução da produtividade total no período que se estende de 1965 a 2010 entre Brasil, Coreia do Sul, Estados Unidos e outros países da américa latina, considerando os efeitos tecnológicos e as mudanças estruturais. Segundo a explicação dos autores, essa decomposição revela-nos se o crescimento de dada economia foi em razão de mudanças estruturais - a realocação da mão de obra de setores menos produtivos para mais produtivos - ou do avanço tecnológico, ou seja, o fato da economia conseguir produzir mais com uma mesma quantidade de insumos. Os autores observam que, apesar da enorme discrepância total entre Coreia do Sul e os demais países, essa evolução apresenta diferentes trajetórias quando analisada em períodos menores. Se até 1980 ambos apresentavam crescimento de produtividade semelhante, encontram que, nos anos 1980, o efeito tecnológico foi o grande responsável pela queda da produtividade brasileira, apesar de ter sido atenuado pelo efeito composição (mudança estrutural), principalmente pelos investimentos das fases que ficaram conhecidas como "Milagre Econômico" e o II Plano Nacional de Desenvolvimento, nas décadas anteriores. Na economia coreana, por outro lado, observou-se crescimento de 65,7\% da produtividade, guiada pela sobressalência do efeito tecnológico. Para os Estados Unidos, observam baixíssimo crescimento no período 1965-1980, relativamente aos demais países (7\%); aumento relativo nos anos 1980 (12\%); e retomada considerável nos anos que se estendem de 1990 a 2010 (28\%).

No âmbito setorial, a partir dos dados das Contas Nacionais e da Pesquisa Nacional por Amostra de Domicílio, Veloso et al. (2015) atualiza a trajetória da evolução da produtividade do trabalho no Brasil ao longo dos anos 1990 e 2000. Os autores mostram que a produtividade média do trabalho cresceu à taxa de 1,3\% a.a. (1995-2013), com diferença considerável entre os três principais setores da economia: Agropecuária (6, $1 \%$ a.a.); Indústria (-0,4\% a.a.); e Serviços (0,6\% a.a.).

Regionalmente, Galeano e Feijó (2013) fazem a análise de decomposição da evolução da produtividade do trabalho na indústria entre 1996 e 2007, considerando a participação desta no emprego nacional pelo método shift-share. De interesse para o presente trabalho, destacam-se os valores encontrados para cada macrorregião do país: Sudeste, -12,4\%; Sul, 14,6\%; Norte, 58,3\%; Nordeste, 23,9\%; e Centro-Oeste, $55,5 \%$. Segundo os autores, os resultados gerais mostram que houve certo rearranjo de alguns setores da indústria entre as regiões. No entanto, as regiões menos desenvolvidas ainda não conseguem absorver aquela parcela dos setores em declínio na região Sudeste, devido à baixa representatividade das atividades industriais nas regiões. Com exceção da região sudeste, os autores defendem que o crescimento da produtivi- 
dade do trabalho nos anos analisados tenha se dado mais por causa da componente regional residual, ou seja, da competitividade dos próprios setores nas regiões, do que mudanças estruturais na composição setorial.

Nesse sentido, Cruz e Santos (2011) analisam a dinâmica do emprego industrial brasileiro entre 1990 e 2009 e destacam que, apesar de ter havido desconcentração regional do emprego industrial, as regiões que possuíam uma base industrial relevante caminharam em direção à especialização em indústrias de maior conteúdo tecnológico, como uma consequência das externalidades desses locais que, de acordo com os autores, foi mais importante do que os incentivos fiscais oferecidos à dispersão. Mendes et al. (2019) avaliam a reorganização espacial da indústria de transformação brasileira pós-2008 e sugerem uma desconcentração da atividade produtiva enviesada para o emprego de pior qualidade, com maior dispersão de setores de menor intensidade tecnológica e de empregos com menores níveis educacionais. Os autores assumem uma forte correlação entre intensidade tecnológica setorial e grau de instrução do trabalhador e observam destaque da região Sudeste, principalmente do estado de São Paulo, no que se refere à geração de emprego de mestres e doutores, em setores de mais elevada intensidade tecnológica. Para além da questão setorial, os resultados encontrados ainda sugerem uma possivel transição produtiva em busca de menores custos de mão de obra.

É importante enfatizar que a dinâmica da produtividade do trabalho ao longo do tempo, de modo geral, esteve intimamente relacionada ao crescimento do produto e renda dos países. Para o Brasil, vale lembrar que esta convergência regional, decorreu, historicamente, de fatores relacionados com a ação da política econômica e com

a lógica econômica da competição e da localização. Conforme destacam Ferreira e Diniz (1995), a convergência de renda per capita entre os estados brasileiros nas décadas de 1970 e 1980, período de maior efetividade da descentralização industrial no país, esteve associada ao desenvolvimento e a ampliação da infraestrutura básica; ao movimento das fronteiras agrícola e mineral; à ação direta do Estado em termos de investimentos e concessão de subsídios e incentivos fiscais; às crises e reversões da polarização industrial nos grandes centros urbanos como Rio de Janeiro e São Paulo; e aos movimentos migratórios e alterações na distribuição regional da população. Condicionantes estes alinhados às investigações feitas, mais recentemente, para a indústria brasileira, como indicam os trabalhos anteriormente mencionados.

\section{Metodologia, base de dados e estratégia de simulação}

O modelo usado para as simulações é um modelo de EGC dinâmico recursivo calibrado para o Brasil. Ele segue a estrutura teórica do The Enormous Regional Model (TERM), que é um modelo desenvolvido pelo Center of Policy Studies (CoPS), na Austrália, com várias aplicações para a economia brasileira, incluindo Ferreira Filho e Horridge (2014) ; Carvalho et al. (2017); Ribeiro et al. (2018); Cardoso et al. (2019). Como discutido a seguir, o método empregado no presente estudo se difere pelo pe- 
ríodo das informações utilizadas na construção da base de dados e pelo detalhamento regional da mudança tecnológica no trabalho, de modo a favorecer o potencial analítico das simulações no âmbito regional.

\section{The Enormous Regional Model (TERM)}

O TERM é um modelo regional de Equilíbrio Geral Computável bottom-up, o que significa que cada região do modelo é considerada como uma economia separada, os resultados à nível nacional são agregações dos resultados regionais. Embora a demanda, oferta, preço e quantidade sejam computados para cada região separadamente, a interdependência espacial é considerada no modelo por meio do comércio inter-regional. Portanto, a abordagem do TERM favorece analises nas quais o detalhamento setorial e regional possui papel relevante.

A estrutura teórica do TERM segue pressupostos neoclássicos básicos. Para cada unidade federativa, uma família representativa escolhe uma cesta de consumo que maximiza uma função de utilidade Stone-Geary sujeita a uma restrição orçamentária, o consumo pode ser dividido entre o componente de subsistência e de luxo (supernumerário), no qual apenas gastos superiores ao nivel de subsistência afetam a utilidade per capta (Peter et al., 1996)(Stone, 1954). Todos os agentes econômicos (famílias, empresas, governo e investidores) podem escolher entre bens domésticos (de diferentes fontes regionais) e bens importados usando uma especificação da CES (hipótese de Armington), com base nas diferenças de preço de compra de cada fonte. A condição de market-clearing é válida para todos os mercados em todos os períodos, ajustando preços e quantidades a cada ano.

O mecanismo que modela a tecnologia de produção é o principal canal de transmissão de efeitos para o exercício proposto no presente estudo, sua estrutura define a produção de cada setor e região por meio da minimização dos custos de produção, seguindo uma função de produção em proporções fixas do tipo Leontief, que estabelece o uso de insumos intermediários e fatores primários (1). Combinada hierarquicamente com a função de produção, uma função de elasticidade constante de substituição (CES) define a composição dos fatores primários, trabalho e capital, empregados na produção (2). Estão associadas a cada um dos insumos, sejam intermediários ou fatores primários, variáveis de mudança tecnológica que possibilitam capturar os efeitos de ganhos ou perdas de produtividade no seu uso. Nesse sentido, ganhos de produtividade podem ser entendidos como poupadores de insumos/fatores.

$$
\begin{gathered}
t o t_{s r}^{q}=\frac{1}{\operatorname{tot}_{s r}^{t}} \times M I N\left\{\frac{i n t_{s r}^{q}}{i n t_{s r}^{t}}, \frac{\operatorname{prim}_{s r}^{q}}{\operatorname{prim}_{s r}^{t}}, \frac{o u t_{s r}^{q}}{o u t_{s r}^{t}}\right\} \\
\operatorname{prim}_{s r}^{q}=C E S\left\{\frac{\operatorname{trab}_{s r}^{q}}{\operatorname{trab}_{s r}^{t}}, \frac{\operatorname{cap}_{s r}^{q}}{\operatorname{cap}_{s r}^{t}}\right\}
\end{gathered}
$$


Nas equações, $q$ denota quantidade; $t$, tecnologia; $s$, setor; e $r$, região; int, prim, e out indicam os insumos intermediários, fatores primários e outros custos de produção, respectivamente; trab e cap indicam o uso do fator primário trabalho e o uso do fator primário capital, respectivamente; $t o t_{s r}^{q}$ denota a quantidade total produzida pelo setor $s$, na região $r$; e $t o t_{s r}^{t}$ é a variação tecnológica no uso dos insumos totais no setor $s$ na região $r$.

O ajuste da dinâmica recursiva do modelo se baseia na acumulação de investimentos e estoque de capital nos níveis regional e setorial. Seguindo Dixon e Rimmer (2002), em cada ano de simulação, supõe-se que as taxas de crescimento de capital sejam determinadas pela disposição dos investidores em aplicar recursos em determinado setor com base na taxa de retorno esperada. Basicamente, se a taxa de retorno esperada pelos investidores for maior que a taxa normal de retorno pré-estabelecida, a acumulação de capital estará acima da taxa normal (Dixon e Rimmer, 2002).

Nesse sentido, o exercício proposto é favorecido pela capacidade do método de capturar, no tempo, os efeitos de mudanças tecnológicas diferenciadas a nível regional sobre o sistema econômico, assim como pela possibilidade de decomposição dos seus efeitos entre os principais agregados macroeconômicos como o consumo, investimento, emprego, exportações e importações.

\section{Base de dados}

A base de dados do modelo é composta por 27 regiões, que correspondem as Unidades da Federação do Brasil, e 127 setores, discriminados na Matriz de Insumo Produto 2015 divulgada pelo Instituto Brasileiro de Geografia e Estatística (IBGE) (IBGE, 2018). A base foi construída por meio de um procedimento de regionalização criado por Horridge (2012). Além de informações do Sistema de Contas Nacionais (SCN) do Brasil, foram utilizados dados adicionais em nivel regional, que incluem informações sobre consumo da Pesquisa de Orçamento Familiar do Brasil 2008-2009 (IBGE, 2011); emprego, na Relação Anual de Informações Sociais (RAIS) (Brasil, 2020); e comércio internacional, com base nas informações do Comex Stat (Brasil, 2019).

A seguir, analisam-se algumas variáveis da base de dados do modelo que são importantes para este estudo: a distribuição nacional do PIB por estado (Figura 1), a remuneração do fator trabalho nos estados (Figura 2) e a representatividade dos gastos do Governo, por setor governamental, em relação a produção total nas UFs (Figuras 3 e 4).

A Figura 3 exibe um panorama do papel do Governo. No modelo utilizado, os gastos públicos são tomados no conceito de Governo Geral, isto é, representam o gasto total das esferas Federal, Estadual e Municipal. A parte (a) ilustra a composição dos principais fluxos de compra dos setores governamentais enquanto demandante de produtos; em (b), verifica-se o peso dos gastos na produção total regional, por setor. 
Figura 1. Produto Regional Bruto (R\$ milhões), Brasil, 2015.

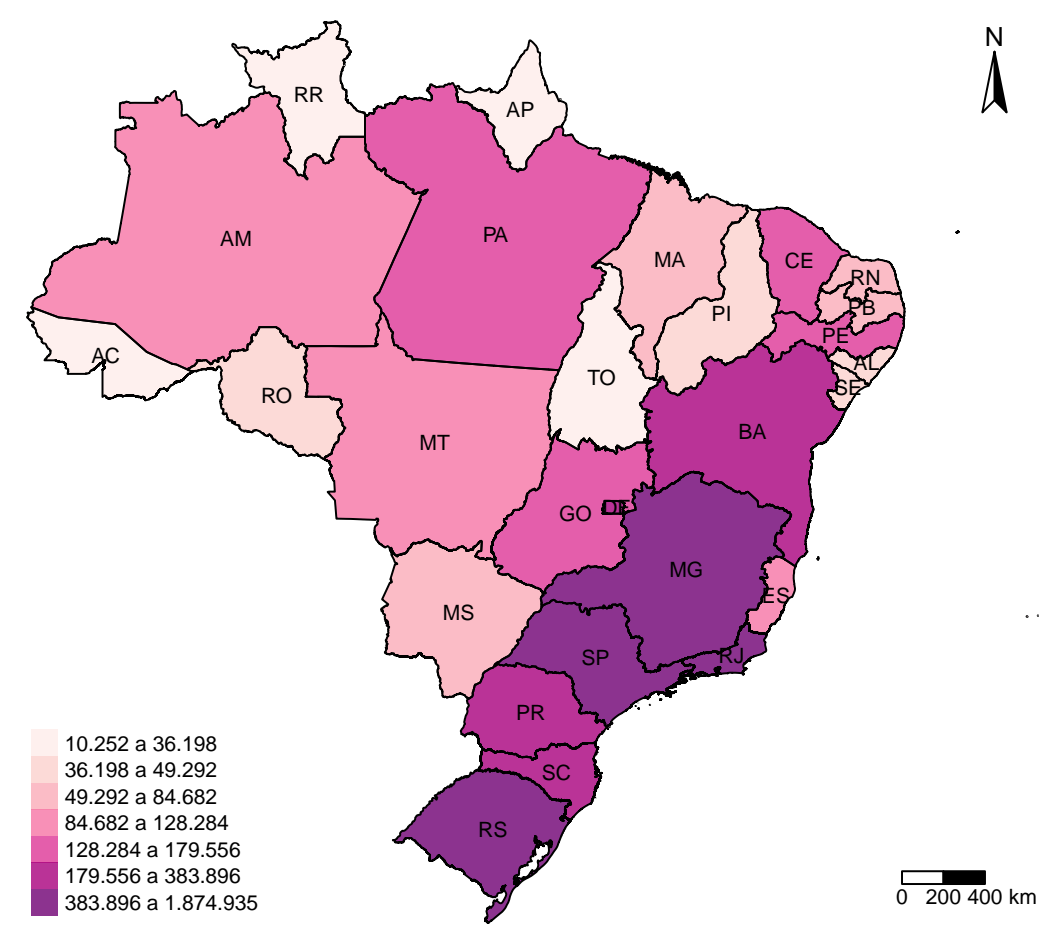

Fonte: Elaboração própria com base nos dados do modelo.

Figura 2. Remuneração agregada do fator trabalho nas UFs (R\$ milhões), Brasil, 2015.

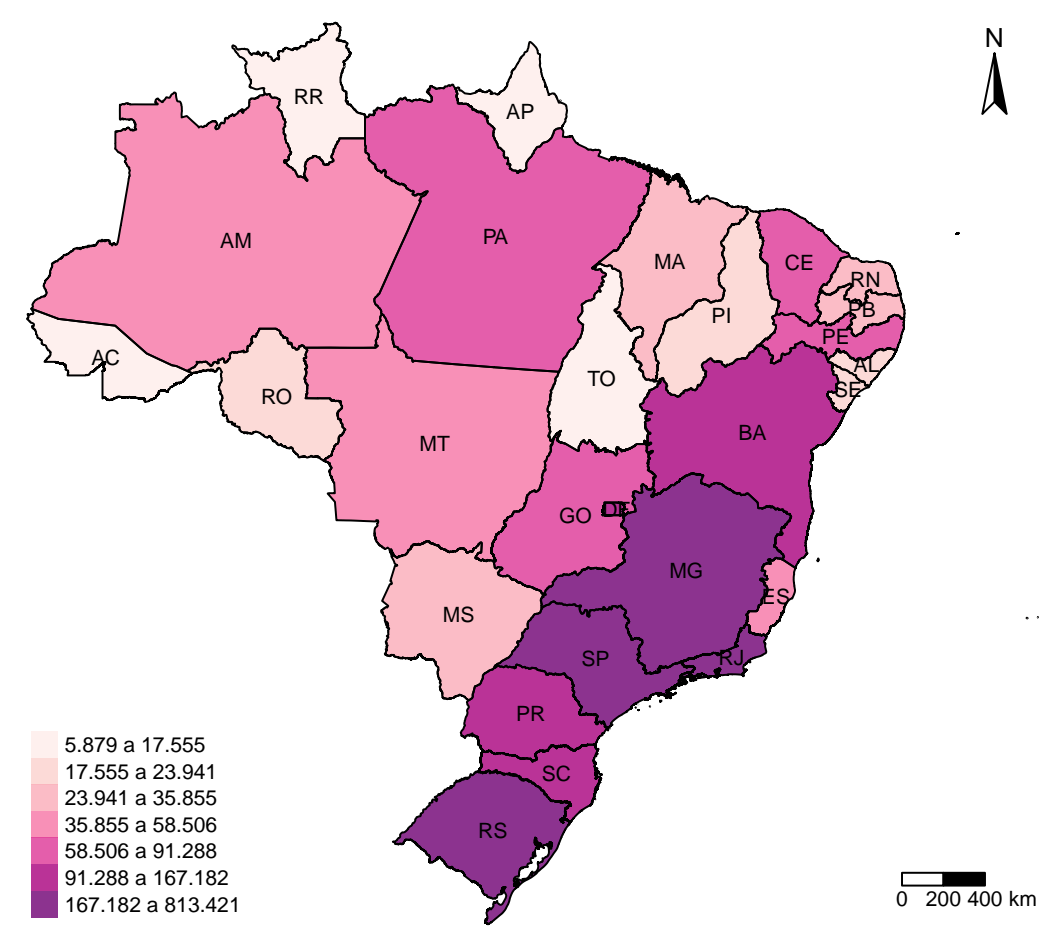

Fonte: Elaboração própria com base nos dados do modelo. 
Figura 3. Principais demandas dos setores governamentais por produtos (a) e participação dos gastos dos setores governamentais na produção total das UFs (b).

(a)

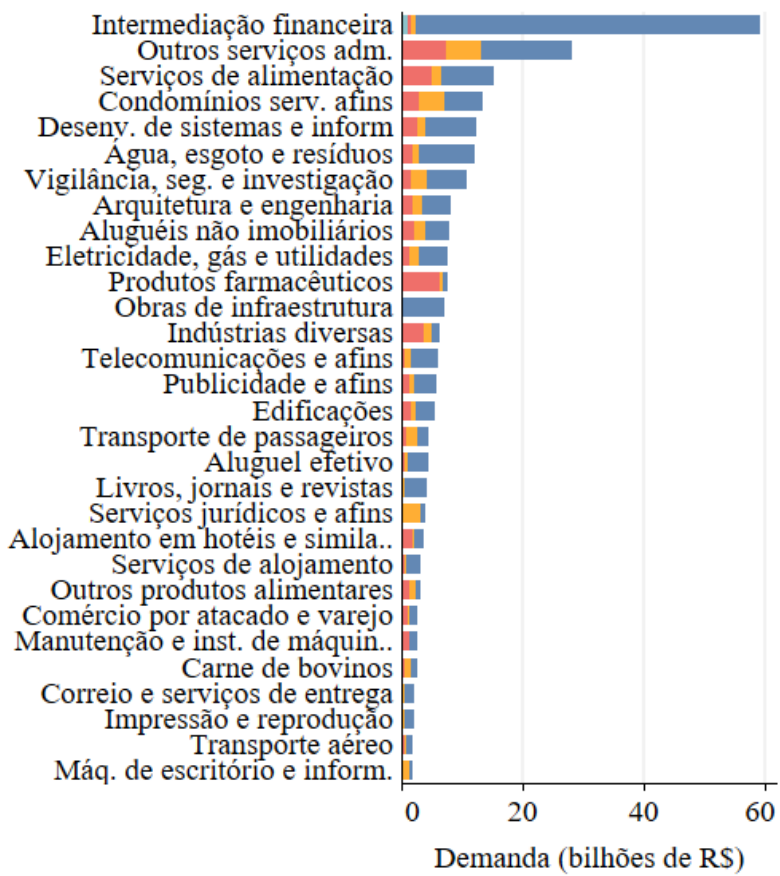

(b)

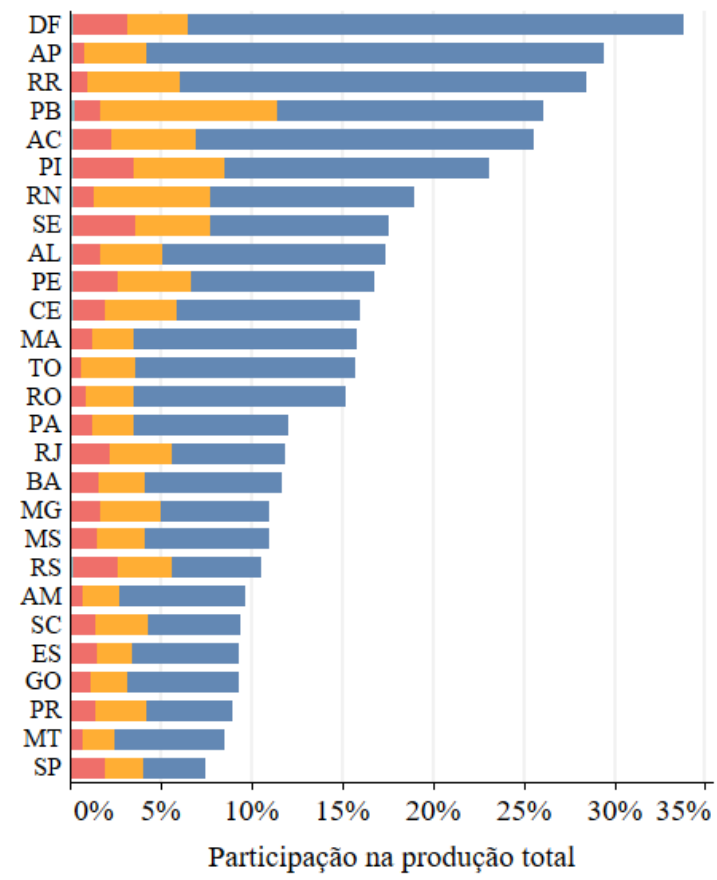

Serv. de previdência e assist. social Saúde pública

\section{Setores governamentais}

Fonte: Elaboração própria com base nos dados do modelo.

O que se pode notar é que, enquanto os gastos do Governo têm maior participação na produção total do Norte e Nordeste do país ${ }^{3}$, a remuneração do trabalho concentrase nos estados de maior PIB, principalmente nas regiões Sul e Sudeste. A Figura 4 exibe a participação do componente dos gastos do Governo Geral no produto total de cada UF.

De forma geral, as ilustrações indicam que a maior participação do consumo do setor público (gastos em bens e serviços) nessas regiões tornam a sua dinâmica econômica mais dependente desse componente da demanda final. Além disso, o setor Administração Pública tem elevada participação no emprego e na massa de salários dessas regiões, o que também condiciona a dinâmica da economia desses estados.

\section{Estratégia de Simulação}

Para avaliar a resposta da variação na produtividade da mão-de-obra necessária para compensar o impacto contracionista da redução do tamanho do Estado na economia, influenciado pela duradoura agenda de austeridade fiscal adotada atualmente

\footnotetext{
${ }^{3}$ Ressalva ao Distrito Federal, local de trabalho de grande parte do funcionalismo público da esfera federal do país.
} 
Figura 4. Representatividade do componente dos gastos do Governo Geral no Produto Regional Bruto, por UF (\%), Brasil, 2015.

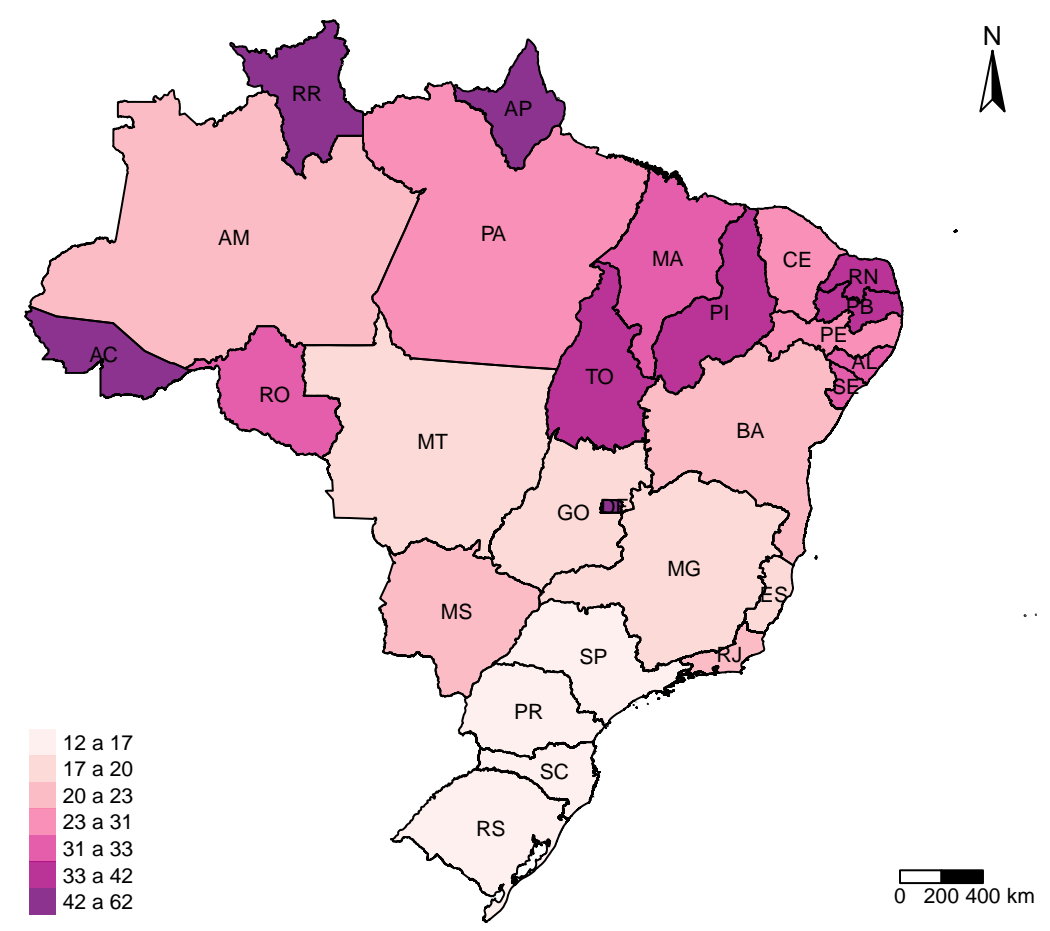

Fonte: Elaboração própria com base nos dados do modelo.

no país, a simulação é dividida em um cenário base e um cenário de política. A simulação do cenário base atualiza o banco de dados da seguinte forma: para o período observado (2016-2019), foi utilizado os principais dados macroeconômicos oficiais para PIB real, investimento, consumo das famílias, gastos do Governo, exportações, preços de importação e índice de preços ao consumidor. Para o período 2020-2021, fez-se uso de um cenário homogêneo de crescimento a $1 \%$ e 1,5\%, para esses anos, respectivamente, e, a partir de 2022, assumimos um cenário de crescimento estacionário de $2,5 \%$ ao ano. A partir de 2020 , adota-se também no cenário base a hipótese de o crescimento dos gastos do governo seguir a taxa de crescimento do consumo das famílias.

Para a simulação da política, o crescimento do consumo real do governo geral, exógeno, foi programado para uma taxa de crescimento nula, representando o comprometimento nos moldes do ajuste fiscal iniciado em 2015 e aprofundado em 2016 com a aprovação da Emenda Constitucional 95/2016. Em outras palavras, não há crescimento real dos gastos do governo no cenário de política. Essa premissa é mantida constante ao longo de todo período de simulação (2019 a 2030). O cenário de política não pretende simular, estritamente, a atuação da EC 95/2016, mas de uma hipotética agenda de austeridade geral, representada pela ausência de crescimento real dos gastos do Governo Geral. Isso implica que o setor institucional Governo Geral perde participação no PIB do país ao longo do período de simulação. 
Conforme já ressaltado, na base de dados do modelo utilizado, diferentemente daquilo estabelecido pela EC 95/2016, os gastos governamentais estão definidos pelo conceito fiscal de Governo Geral, isto é, congrega os gastos de consumo intermediário do Governo e pessoal das esferas Federal, Estadual e Municipal. O cenário de política representa, portanto, um cenário ilustrativo de redução do tamanho do Estado em relação à economia, já que as UFs e os municípios não estão, a princípio, no teto de gastos $^{4}$.

Além da base de dados, o funcionamento dos modelos de EGC depende de um grande sistema de equações, em que se estabelecem o comportamento das variáveis e suas interrelações. A principal equação envolvida no choque de política a ser estudado é simples:

$$
P I B_{r}=C_{r}+G_{r}+I_{r}+X_{r}-M_{r}
$$

Conforme explicado anteriormente, a simulação proposta consiste numa redução relativa dos gastos do Governo $(G)$ frente ao cenário base, para cada região $r$. No entanto, para a avaliar a reação da produtividade do trabalho frente à contração dos gastos, altera-se o chamado "fechamento" do modelo.

O fechamento é o conjunto de hipóteses do modelo, em que se define as variáveis exógenas e endógenas do sistema de equações. Para simular o efeito esperado das reformas estruturais adotadas em paralelo à consolidação fiscal, modificou-se o fechamento do cenário de política de modo a permutar o PIB real de cada UF, exógeno, com a respectiva produtividade do trabalho, endógena, ao passo em que se estabelece crescimento inalterado da primeira variável com relação ao observado no cenário base. Ou seja - evita-se uma definição ad hoc calculando endogenamente a produtividade do trabalho necessária para manter o crescimento do PIB conforme projetado no cenário base. Em suma, conforme a equação 3, a simulação de política assume o crescimento zero dos gastos do Governo $(G)$ e "desvio zero" do PIB com relação ao cenário base, sustentado pelos demais componentes da equação que se ajustam ao aumento de produtividade esperado descrito nas equações 1 e $2^{5}$.

É importante enfatizar que, na metodologia utilizada, os detalhes da dinâmica do mercado de trabalho e do salário real, referente à dinâmica recursiva do modelo, indi-

\footnotetext{
${ }^{4}$ Houve pressão para que os Estados aderissem ao teto em troca do adiamento do pagamento dos vencimentos da dívida com a União. O Plano de Recuperação Fiscal, por exemplo, estava sendo proposto pela União aos Estados em troca das negociações a respeito do auxílio federal à situação fiscal dos Estados. Este plano seguia basicamente as estratégias da EC 95, como o crescimento real nulo das despesas. Mas, dada a dificuldade de decisão por parte do legislativo dos Estados e a chegada da crise da pandemia de Covid-19, não foi estabelecido nada concreto. Em 11/03/21 foi aprovada a PEC 189 (PEC Emergencial), que coloca regras de austeridade para os Estados e municipios, que devem ser tomadas caso as despesas correntes desse ente em relação às receitas correntes ultrapassarem 95\%.

${ }^{5}$ Segundo Cardoso (2019) e Cardoso et al. (2019), devido à contração relativa de demanda agregada, um cenário de política com gastos do Governo crescendo abaixo do projetado no cenário base leva ao desvio negativo do PIB e seus componentes, com exceção das Exportações, no resultado acumulado. No cenário base, o componente de gastos do Governo segue a dinâmica do PIB em cada região.
} 
cam que o ajuste intertemporal dos salários reais responde às flutuações do emprego corrente, tendo em vista o emprego tendencial definido por projeções de crescimento da população economicamente ativa, presente no cenário base. Outro fato importante é que, no modelo de equilíbrio geral computável empregado, o simples anúncio dessa política tem apenas o efeito de alterar a demanda agregada, mas não as expectativas em relação à taxa de juros e investimento. Portanto, pode-se dizer que nosso cenário de política simula o que aconteceria se o governo mantivesse seu compromisso com relação ao crescimento nulo dos gastos reais, mas famílias e empresas, no entanto, não mudassem suas expectativas em relação ao futuro ${ }^{6}$.

\section{Resultados}

Nesta seção, os resultados da simulação de política são apresentados sob três perspectivas: i) nível macroeconômico nacional e regional, mostrando o impacto acumulado nos componentes do PIB e no emprego (2019-2030); ii) produtividade do trabalho no nível estadual; e iii) resultados setoriais a nível estadual. Todos os resultados são exibidos em desvio percentual acumulado com relação ao cenário base de referência, aquele em que a política de austeridade não se verifica. A Figura 5 apresenta os resultados dos componentes do PIB ao longo da projeção. A Figura 6 exibe a evolução de outras variáveis macroeconômicas, importantes para a interpretação dos resultados da Figura 5.

Conforme ilustrado nos gráficos anteriores, um choque de retração da demanda total do Governo (Figura 5) contribui para a queda da demanda agregada e, consequentemente, do índice de preços internos (IPC, na Figura 6), impactando positivamente no saldo comercial ao tornar as exportações mais competitivas via preço no mercado externo e as importações menos competitivas no mercado doméstico (Exportações e Importações, na Figura 5). Aqui, assume-se a hipótese de que o país não exerce influência no mercado global, de modo que as exportações crescem mais que as importações, revertendo o deficit marginal do cenário base. À essa condição, alia-se, ainda, o fato de o aumento da produtividade contribuir para diminuição dos custos de produção.

O consumo das famílias mantém-se praticamente equiparado ao projetado no cenário base (desvio acumulado final de -0,02\%, na Figura 5), apesar da queda do nível de emprego (Figura 6). Este resultado se deve ao fato de o ganho de produtividade do trabalho sustentar o nível médio dos salários a cada ano, descolando-os do nível de preços internos (Figura 6). Os resultados estaduais exibidos na Tabela 1, no entanto, mostram que o consumo varia consideravelmente entre os estados.

\footnotetext{
${ }^{6} \mathrm{O}$ modelo possui elementos de dinâmica recursiva similares aos de Dixon e Rimmer (2002). Dessa forma, a simulação de política representa um desvio percentual em relação ao cenário base, e este desvio não é influenciado pelas características do cenário base. Esta característica decorre da estrutura teórica do modelo (dinâmica recursiva), do método de solução (sistema de equações linearizadas) e do fechamento adotado (definição de variáveis exógenas e endógenas). Portanto, diferentes cenários base de crescimento para o PIB não modificariam o desvio entre cenário base e cenário de política.
} 
Figura 5. Resultados Macroeconômicos - Cenário de Política - Desvio acumulado relativamente ao cenário base (\%) (2019-2030)

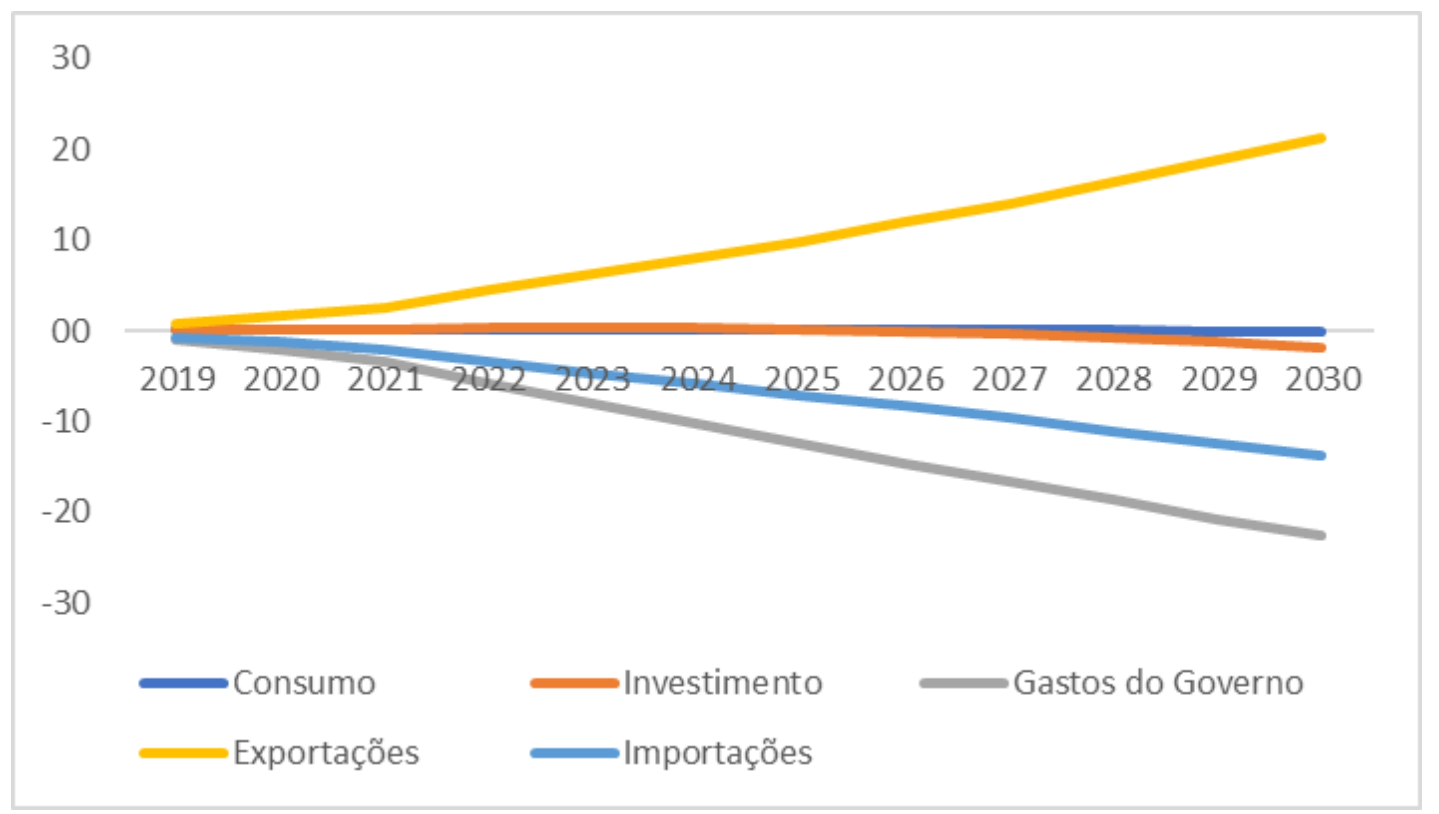

Fonte: Elaboração própria com base nos resultados da simulação.

Figura 6. Outros resultados macroeconômicos - Cenário de Política - Desvio acumulado relativamente ao cenário case (\%) (2019-2030)

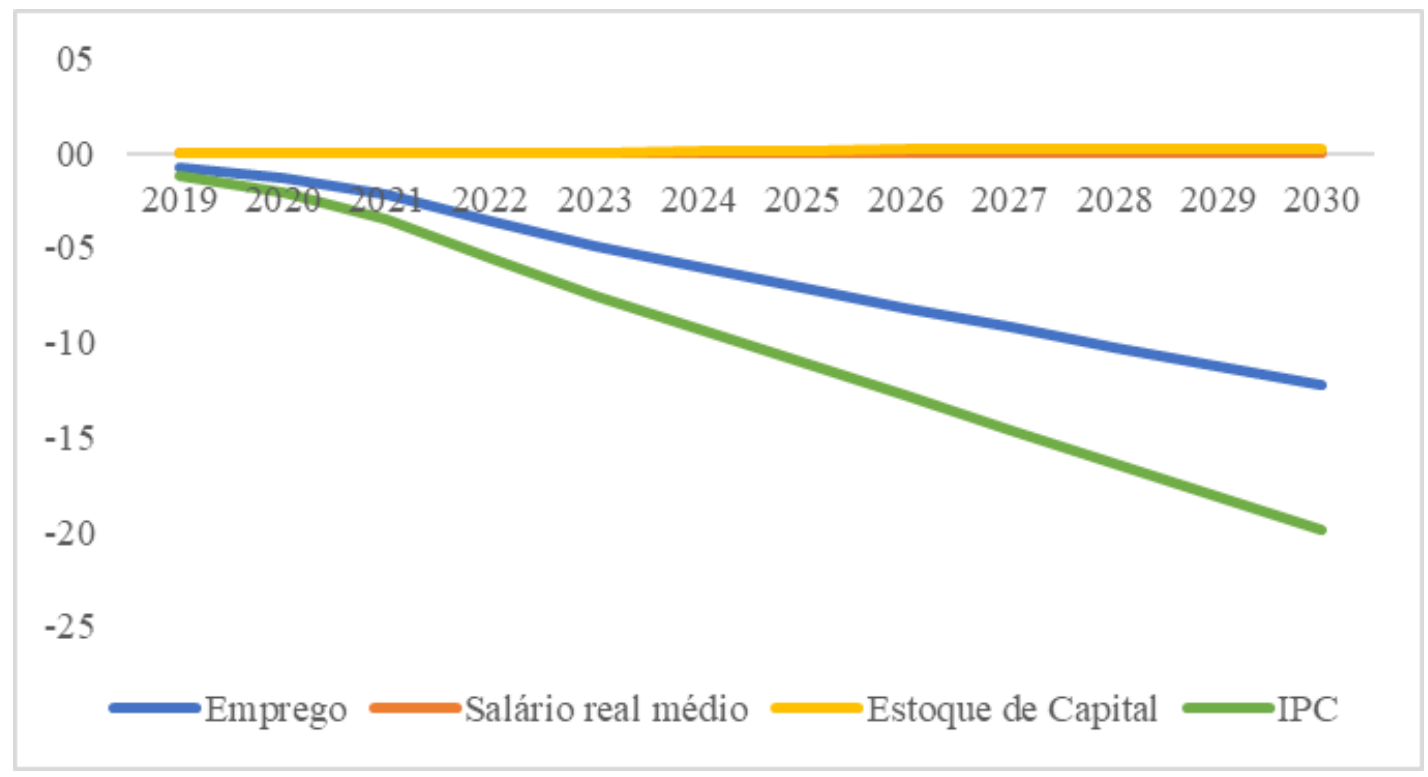

Fonte: Elaboração própria com base nos resultados da simulação.

A estagnação real dos gastos públicos com resposta positiva da produtividade do trabalho também não impulsiona crescimento significativo do investimento (Figura 5). Assim, mesmo com insumos mais baratos e crescimento de setores exportadores, os niveis de renda e consumo influenciam a taxa de retorno do capital e contribuem por manter o investimento em níveis similares ao cenário base, embora haja pequeno desvio negativo nos anos finais da simulação. 
Tabela 1. Resultados Macroeconômicos a nível estadual - Cenário de Política - Desvio (\%) acumulado relativamente ao Cenário Base (2030)

\begin{tabular}{|c|c|c|c|c|c|c|}
\hline UF & $\mathrm{C}$ & I & $\mathrm{G}$ & $\mathrm{X}$ & M & Emprego \\
\hline $1 \mathrm{RO}$ & 0 & -8 & -23 & 28 & -18 & -12 \\
\hline $2 \mathrm{AC}$ & -12 & -14 & -23 & 29 & -24 & -23 \\
\hline $3 \mathrm{AM}$ & 1 & -1 & -23 & 21 & -10 & -11 \\
\hline $4 \mathrm{RR}$ & -9 & -13 & -23 & 31 & -21 & -20 \\
\hline $5 \mathrm{PA}$ & -4 & -3 & -23 & 25 & -17 & -16 \\
\hline $6 \mathrm{AP}$ & -15 & -14 & -23 & 31 & -24 & -26 \\
\hline $7 \mathrm{TO}$ & -3 & -10 & -23 & 26 & -20 & -15 \\
\hline $8 \mathrm{MA}$ & -9 & -8 & -23 & 24 & -20 & -20 \\
\hline 9 PI & -19 & -15 & -23 & 31 & -26 & -29 \\
\hline $10 \mathrm{CE}$ & -15 & -16 & -23 & 41 & -25 & -25 \\
\hline $11 \mathrm{RN}$ & -20 & -23 & -23 & 44 & -29 & -30 \\
\hline $12 \mathrm{~PB}$ & -31 & -33 & -23 & 56 & -36 & -40 \\
\hline $13 \mathrm{PE}$ & -24 & -26 & -23 & 42 & -31 & -34 \\
\hline $14 \mathrm{AL}$ & -15 & -14 & -23 & 38 & -24 & -26 \\
\hline $15 \mathrm{SE}$ & -15 & -10 & -23 & 23 & -19 & -26 \\
\hline $16 \mathrm{BA}$ & -3 & -3 & -23 & 25 & -14 & -15 \\
\hline $17 \mathrm{MG}$ & 2 & 1 & -23 & 22 & -13 & -10 \\
\hline $18 \mathrm{ES}$ & 3 & 0 & -23 & 20 & -12 & -10 \\
\hline $19 \mathrm{RJ}$ & -1 & 0 & -23 & 21 & -13 & -13 \\
\hline $20 \mathrm{SP}$ & 6 & 2 & -23 & 20 & -11 & -7 \\
\hline $21 \mathrm{PR}$ & 4 & 1 & -23 & 21 & -12 & -8 \\
\hline $22 \mathrm{SC}$ & 4 & 0 & -23 & 22 & -12 & -9 \\
\hline $23 \mathrm{RS}$ & 3 & 1 & -23 & 20 & -12 & -9 \\
\hline $24 \mathrm{MS}$ & 0 & 1 & -23 & 23 & -15 & -12 \\
\hline $25 \mathrm{MT}$ & 2 & 1 & -23 & 22 & -14 & -10 \\
\hline $26 \mathrm{GO}$ & 1 & -4 & -23 & 25 & -17 & -11 \\
\hline $27 \mathrm{DF}$ & -14 & -17 & -23 & 29 & -25 & -25 \\
\hline
\end{tabular}

Fonte: Elaboração própria com base nos resultados da simulação.

A nível estadual, os resultados da simulação apresentados na Tabela 1 indicam piora significativa no Consumo das famílias e Investimento nos estados da região Norte, como Acre, Roraima e Amapá, e da região Nordeste que, com exceção da Bahia, acumulam desvios negativos expressivos com relação ao cenário base. Como se pode notar, a estagnação real dos gastos do Governo é de igual magnitude entre os estados, no entanto, seus impactos são distintos dadas as diferentes participações dos setores públicos (Educação pública, saúde pública e Administração pública e seguridade social) em cada uma delas, conforme indicado na seção anterior. As exportações crescem mais nos estados mais atingidos pela política de estagnação dos gastos, em que o desemprego e a queda de consumo e investimento também são maiores, impactando negativamente nos preços internos, contribuindo para o aumento das exportações. As 
heterogeneidades regionais dos resultados implicam que a resposta da produtividade do trabalho necessária para manter o PIB constante acontece de maneira diferenciada nas UFs do país, conforme mostra a Figura 7, a seguir.

Figura 7. Crescimento acumulado da produtividade do trabalho por UF (\%) - Cenário de Política (2030).

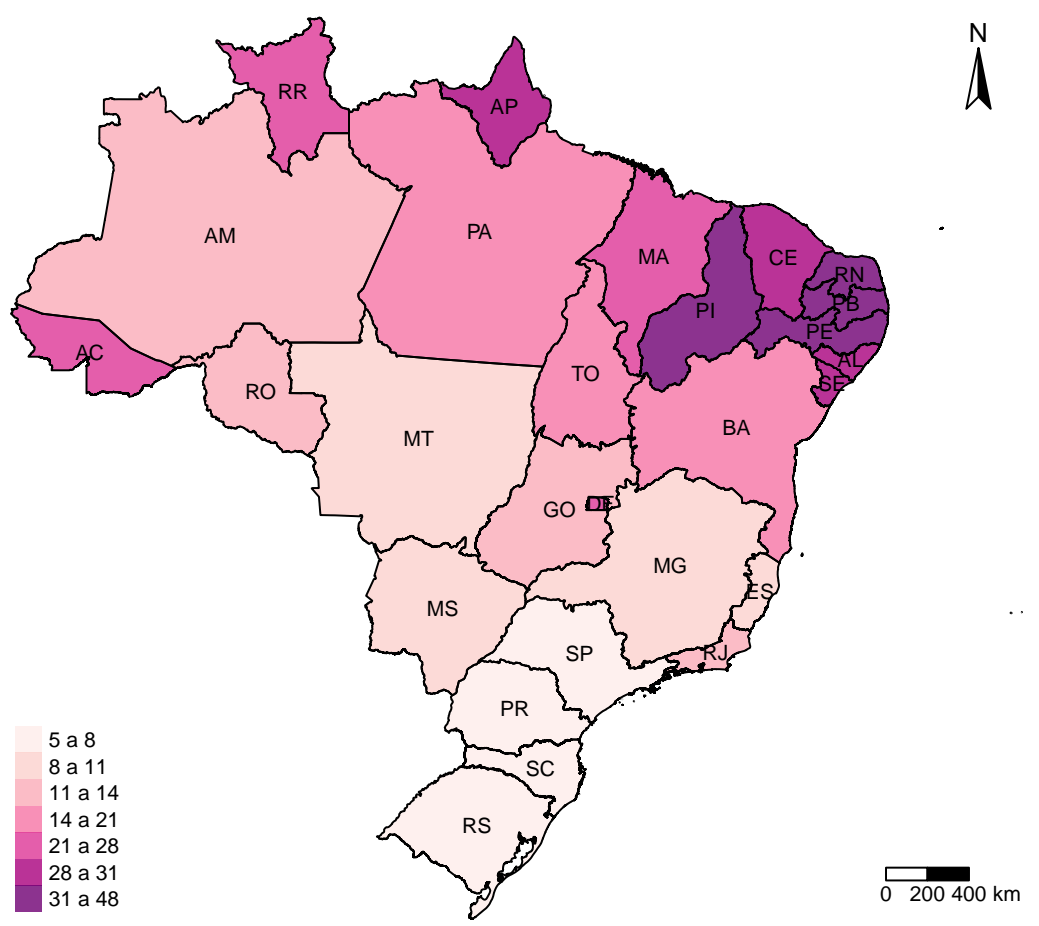

Fonte: Elaboração própria com base nos resultados do modelo.

Nos resultados do modelo, o aumento de produtividade é dado em valores negativos, o que implica a necessidade de menos trabalho para produzir determinada quantidade de produto. De maneira análoga, podemos interpretar os valores positivos como sendo o aumento da quantidade de produto que o mesmo número de trabalhadores estará apto a produzir.

Como se pode observar na Figura 7 , os resultados da simulação mostram que a produtividade do trabalho necessária para sustentar o PIB frente à redução dos gastos do Governo é heterogênea no país. A baixa magnitude do crescimento acumulado nos estados de Sul, Sudeste e Centro-Oeste (com exceção do DF) e alto na maior parte da região Norte e principalmente Nordeste, aponta que, em termos relativos, a limitação do crescimento real dos gastos do Governo em São Paulo e no Piauí, por exemplo, é mais expressiva no segundo, pois representatividade dos gastos do Governo no PIB é muito maior do que no primeiro, de modo a exigir crescimento ainda maior da produtividade do trabalho nessas regiões mais afetadas pela austeridade fiscal. Outra justificativa é respaldada na distribuição regional da remuneração do fator trabalho, mais concentrada nos estados do Sul e Sudeste do país, conforme exposto na seção 3. 
Além disso, os resultados setoriais também apresentam justificativas plausiveis para o resultado heterogêneo da resposta da produtividade do trabalho necessária para manter o PIB constante, dada a redução da participação dos gastos do Governo nos estados, conforme mostram os resultados a seguir.

A Tabela 2 destaca as vinte atividades de maior e menor crescimento acumulado no país ao fim da implementação da política (2030). A lista dos setores que mais se beneficiaram com a política é mais diversificada e apresenta setores predominantemente orientados ao mercado externo, com a maioria pertencentes à indústria extrativa e de transformação. Já a dos setores com pior desempenho acumulado apresenta atividades direcionadas ao mercado interno, como serviços públicos, infraestrutura, aluguéis entre outros serviços e bens de abastecimento.

A representatividade da produção desses setores selecionados em cada estado antes da implementação da política é um importante indicador para justificar os diferentes niveis de produtividade do trabalho necessários para sustentar a atividade econômica, conforme mostrado anteriormente na Figura 7. As figura 8 e 9, a seguir, mostram a participação dos dois grupos de setores na matriz que considera toda a produção da economia, na base de dados do modelo, para cada estado (maior crescimento e menor crescimento, respectivamente).

Como é possível observar, as distribuições da participação dos dois grupos apresentam algumas diferenças importantes. Enquanto as atividades mais beneficiadas após a simulação de política já eram relativamente mais importantes nos estados de São Paulo, Rio de Janeiro, Minas Gerais, Bahia, Amazonas e Pará, as mais prejudicadas aparecem com maior representatividade no Distrito Federal, Piauí, Rio Grande do Norte, Paraíba, Acre, Amapá e Roraima. Enquanto o conjunto de setores mais beneficiados com o cenário de política chega a representar até $10 \%$ da produção em alguns estados (Figura 8), aqueles menos beneficiados podem alcançar representatividade de até 50\% (Figura 9)- resultado representativo da desigualdade de diversificação entre as economias dos estados.

No geral, os resultados são coerentes com a literatura. Desde os anos 1970, uma convergência de renda e atividades produtivas pode ser observada em paralelo ao aumento da produtividade do trabalho nas regiões Norte, Nordeste e, principalmente, Centro-Oeste acima do verificado para as regiões Sul e Sudeste, as mais industrializadas do país. Esse resultado pode ser explicado pelo rearranjo, em certa medida, de alguns setores da indústria entre as regiões. Porém, conforme argumentam autores como Galeano e Feijó (2013) e Mendes et al. (2019), as regiões menos desenvolvidas não conseguiriam absorver a parcela dos setores em declínio na região Sudeste, devido à baixa representatividade das atividades mais tecnológicas nessas regiões, uma vez que a dispersão das atividades tenha ocorrido em busca de menores custos de mão de obra no país. 
Tabela 2. Crescimento setorial - Cenário de Política - Desvio acumulado relativamente ao cenário base (\%) (2030)

\begin{tabular}{|c|c|c|c|}
\hline Melhores resultados & & Piores resultados & \\
\hline Minerais metálicos não ferrosos & 28,3 & $\begin{array}{l}\text { Serviços coletivos da administração } \\
\text { pública }\end{array}$ & $-21,6$ \\
\hline $\begin{array}{l}\text { Serviços de alojamento em hotéis e } \\
\text { similares }\end{array}$ & 28,3 & Educação pública & $-17,7$ \\
\hline $\begin{array}{l}\text { Produtos da metalurgia de metais não } \\
\text { ferrosos }\end{array}$ & 28,1 & $\begin{array}{l}\text { Serviços de previdência e assistência } \\
\text { social }\end{array}$ & $-16,6$ \\
\hline Naftas para petroquímica & 26,9 & Saúde pública & $-13,6$ \\
\hline Carvão mineral & 25,5 & Edificações & $-5,4$ \\
\hline Celulose & 25,4 & Obras de infraestrutura & $-4,2$ \\
\hline Minério de ferro & 24,7 & Saúde privada & $-3,8$ \\
\hline $\begin{array}{l}\text { Defensivos agrícolas e desinfestantes } \\
\text { domissanitários }\end{array}$ & 24,6 & Aluguel imputado & $-3,5$ \\
\hline Produtos químicos orgânicos & 24,2 & Pesquisa e desenvolvimento & -2 \\
\hline Tecidos & 23,7 & $\begin{array}{l}\text { Organizações patronais, sindicais e } \\
\text { outros serviços associativos }\end{array}$ & $-1,7$ \\
\hline Componentes eletrônicos & 23,3 & Gasoálcool & $-0,7$ \\
\hline Ferro gusa e ferroligas & 22,6 & $\begin{array}{l}\text { Caminhões e ônibus, inclusive cabines, } \\
\text { carrocerias e reboques }\end{array}$ & $-0,6$ \\
\hline Produtos químicos inorgânicos & 22,1 & Transporte aquaviário & $-0,3$ \\
\hline $\begin{array}{l}\text { Aluguéis não imobiliários e gestão } \\
\text { de ativos de } \\
\text { propriedade intelectual }\end{array}$ & 21,4 & Outros produtos do laticínio & $-0,1$ \\
\hline $\begin{array}{l}\text { Peças e acessórios para veículos } \\
\text { automotores }\end{array}$ & 21,2 & Outros produtos alimentares & $-0,1$ \\
\hline $\begin{array}{l}\text { Resinas, elastômeros e fibras artificiais e } \\
\text { sintéticas }\end{array}$ & 20,9 & Serviços de alimentação & 0 \\
\hline $\begin{array}{l}\text { Máquinas para a extração mineral e a } \\
\text { construção }\end{array}$ & 20,8 & Móveis & 0,5 \\
\hline $\begin{array}{l}\text { Serviços jurídicos, contabilidade e } \\
\text { consultoria }\end{array}$ & 20,7 & $\begin{array}{l}\text { Outros produtos e serviços da lavoura } \\
\text { temporária }\end{array}$ & 0,9 \\
\hline Combustiveis para aviação & 20,5 & Serviços especializados para construção & 1 \\
\hline $\begin{array}{l}\text { Armazenamento e serviços auxiliares } \\
\text { aos transportes }\end{array}$ & 19,9 & $\begin{array}{l}\text { Produtos derivados do trigo, mandioca } \\
\text { ou milho }\end{array}$ & 1,1 \\
\hline
\end{tabular}

Fonte: Elaboração própria com base nos resultados da simulação.

No atual cenário, como demonstrado neste exercício, o nível de produtividade do trabalho necessário para fazer frente à consolidação fiscal é relativamente mais factível para as regiões onde o gasto do Governo é menos relevante e a estrutura produtiva é ou mais diversificada e mais abundante, em termos de geração de emprego; ou mais beneficiada com a queda dos preços relativos (ou ambas). No entanto, não parece factível tamanho ganho de produtividade nas regiões onde o contrário ocorre: os estados 
Figura 8. Representatividade dos setores de maior crescimento acumulado nas UFs brasileiras (\% do Produto total), 2015.

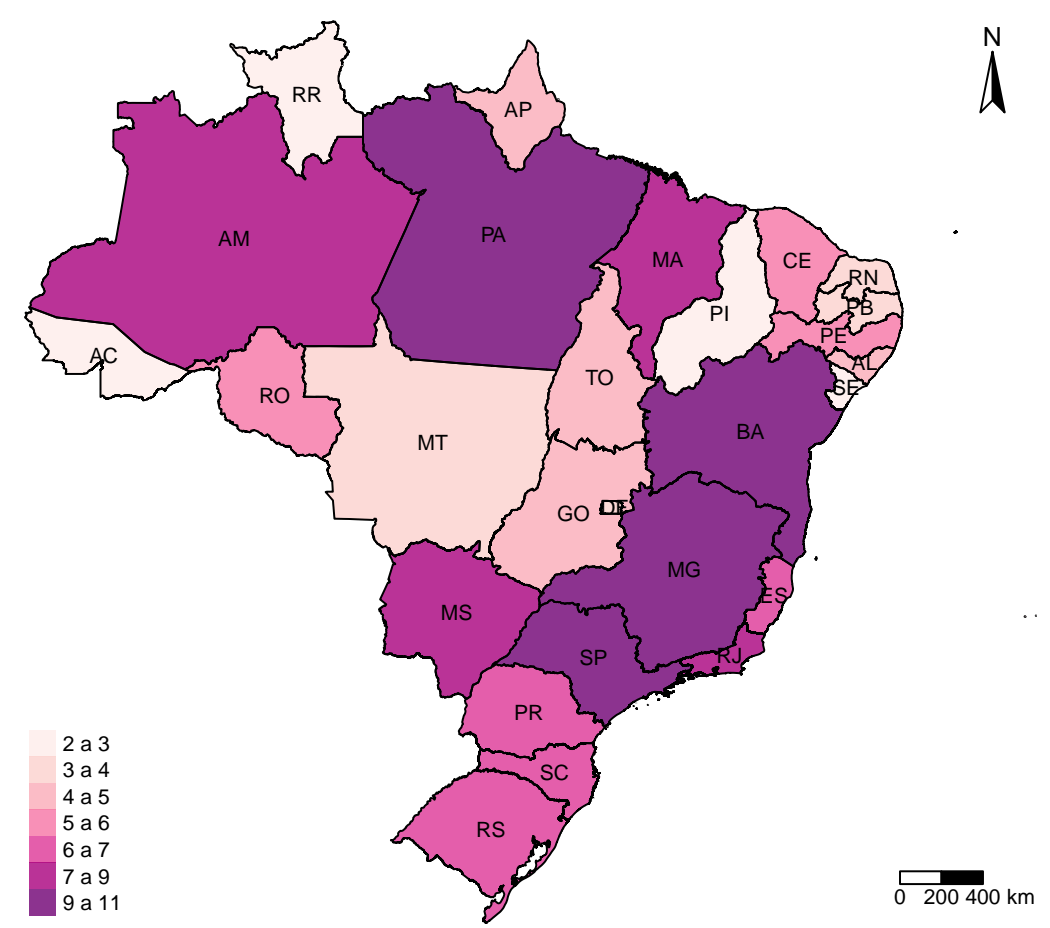

Fonte: Elaboração própria com base nos resultados do modelo.

Figura 9. Representatividade dos setores de menor crescimento acumulado nas UFs brasileiras (\% do Produto total), 2015.

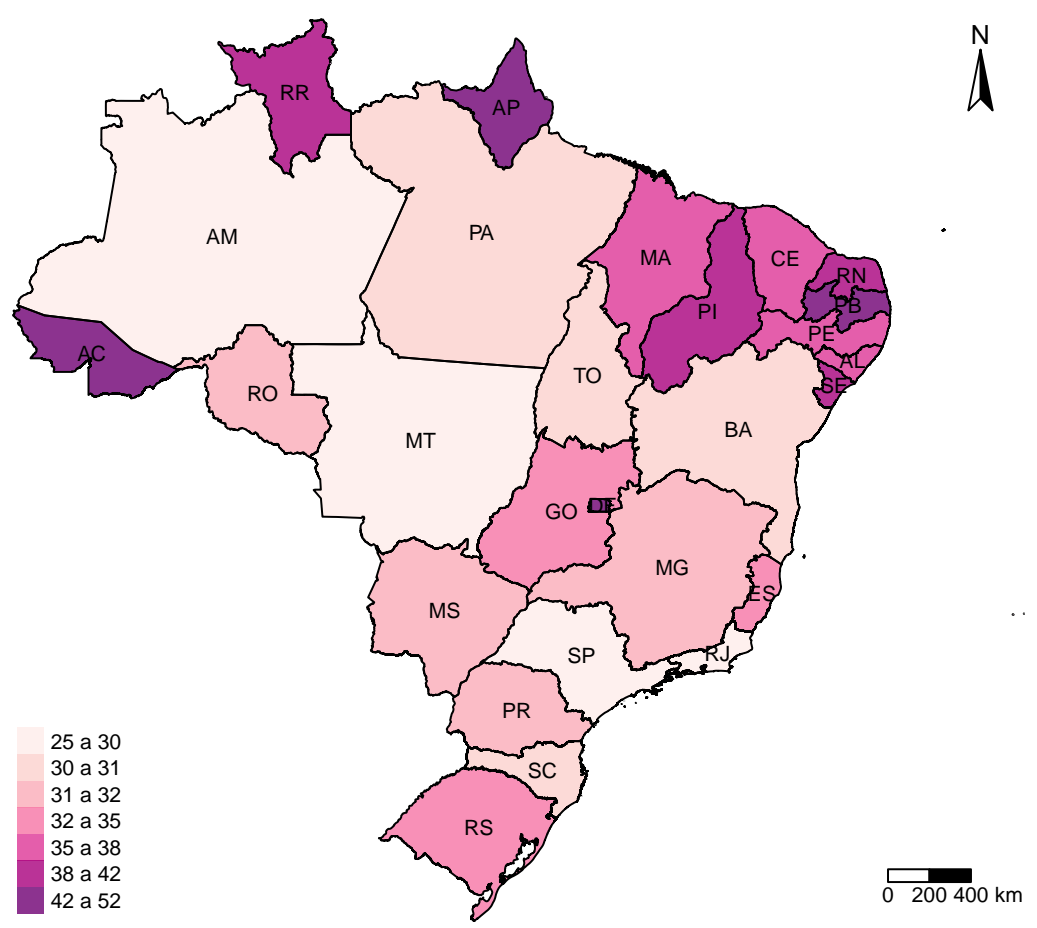

Fonte: Elaboração própria com base nos resultados do modelo. 
das regiões Norte e Nordeste, junto ao Distrito Federal, são os que mais sofrem com a queda acumulada do consumo das famílias, desemprego e, principalmente, investimento - fator chave no histórico de convergência de produção e renda entre as regiões país.

\section{Considerações Finais}

O presente trabalho propôs-se a mensurar a elevação da produtividade do trabalho necessária para compensar a contração do gasto público no Brasil oriunda da atual agenda de austeridade fiscal e reformas estruturais. O objetivo é amparado na hipótese de que reformas estruturais atenuam o efeito da austeridade via elevação da produtividade do trabalho. Por outro lado, observou-se a necessidade de se atentar para as regionalidades brasileiras, uma vez que a estrutura produtiva - bastante desigual no país - desempenha papel importante na reação e recuperação das economias perante a choques multidimensionais como os verificados em consolidações fiscais.

A literatura econômica é permeada por argumentos favoráveis e contrários ao logro das reformas estruturais no âmbito da produtividade do trabalho e nível de produção da economia. Fatores como a dificuldade de planejamento e orientação das reformas, bem como o lento processo de retomada do crescimento em períodos de austeridade, são os principais entraves elencados na literatura. No âmbito regional, encontrase, ainda, argumentos que prezam pela estratégia de desenvolvimento e investimento estatal no que diz respeito à convergência da produção e produtividade. No Brasil, foram esses fatores que marcaram a industrialização de regiões historicamente menos desenvolvidas, como Norte e Nordeste do país. Nesse sentido, a capacidade de sustentação da convergência é um alerta comum entre os autores, que destacam a baixa infraestrutura e educação necessárias para consolidação da indústria de alta tecnologia nessas regiões emergentes.

Os resultados obtidos com a estratégia de simulação utilizada para o modelo de equilíbrio geral computável com dinâmica recursiva e calibrado para as 27 UFs encontram resultados coerentes com a literatura. A produtividade do trabalho necessária para sustentar o PIB frente à redução dos gastos do Governo é espacialmente heterogênea no país. No âmbito macroeconômico, verificou-se queda relativa dos preços, investimento, emprego e importações, enquanto as exportações foram estimuladas pela política simulada. O consumo das famílias manteve-se equiparado ao projetado no cenário base, pois, apesar da queda do nível de emprego, o ganho de produtividade do trabalho contribuiu para sustentar o nível médio dos salários, descolando-os do nível de preços internos. A nível estadual, no entanto, verificou-se redução acentuada no consumo da maioria dos estados das regiões Norte, Nordeste e do Distrito Federal. A queda do investimento e emprego também foi muito maior nessas regiões.

Além da justificativa apoiada na heterogeneidade da representatividade dos gastos do Governo no PIB de cada estado e da distribuição da mão de obra no país, o 
desempenho setorial é também um importante fator para os resultados desiguais da resposta da produtividade em cada estado. A lista dos setores que mais se beneficiariam com a política simulada é mais diversificada, com a maioria das atividades pertencentes à indústria extrativa e de transformação, e mais representativas nos estados onde a necessidade de compensação da produtividade do trabalho é menor. Já a dos setores com pior desempenho acumulado, que apresenta, de forma geral, atividades mais direcionadas ao mercado interno, são mais representativos nos estados mais afetados, negativamente, pela política.

O rearranjo da produção e do trabalho entre as regiões do país esteve historicamente relacionado à ação da política econômica e à lógica econômica da competição e da localização. Mais recentemente, para a indústria brasileira, pode-se afirmar que as economias de aglomerações e bases industriais pré-existentes foram fundamentais para a expansão da mesma, enviesando eventuais desconcentrações da atividade produtiva para empregos de pior qualidade. Portanto, a baixa perspectiva do consumo das famílias juntamente à combinação de ausência de investimentos e elevado desemprego em uma composição setorial pouco beneficiada pela agenda de austeridade e reformas, como evidenciado nos resultados do trabalho, torna inviável tamanho aumento da produtividade do trabalho nos estados das regiões, sugerindo piora na desigualdade regional brasileira.

Na medida em que a austeridade surte efeito, segundo parte da literatura econômica, em variáveis como juros, inflação e controle do endividamento, os resultados aqui apresentados mostram vulnerabilidade regional devido, principalmente, à estrutura produtiva - combinada ao elevado desemprego e queda de consumo das famílias. Assim, as conclusões do presente estudo se juntam às daqueles que defendem a flexibilização das políticas de austeridade em razão do investimento público que vise a diversificação setorial e ampliação da infraestrutura, principalmente nas regiões Norte e Nordeste do país. Além disso, sugere a necessidade de manutenção de políticas de geração de renda via assistência social e empregos formais.

Vale ressaltar algumas limitações do trabalho. O modelo de EGC utilizado não possui um módulo fiscal. Portanto, não temos transferências entre governos e instituições (como famílias) e governos locais. Além disso, não há conexão direta entre as receitas fiscais e despesas públicas, que são determinadas exogenamente. Devido às especificidades das estatísticas do Sistema de Contas Nacionais, o modelo também não capta os efeitos diretos das cortes nos serviços públicos na cesta de consumo das famílias, apenas os efeitos indiretos, via atividade econômica. Não se considera, portanto, um conceito de renda ampliada, como proposto em Atkinson (2015), em que contabiliza o consumo de bens públicos na renda das famílias. Este pode ser um ponto de partida para trabalhos futuros.

Para concluir, ressalta-se o fato da atual crise causada pela pandemia COVID-19 ter exposto as vulnerabilidades dos países cujo papel de atuação do Estado tenha sido mitigado por políticas de austeridade. Os efeitos da pandemia são sistêmicos, 
mas requerem atenção especial em relação ao já fragilizado mercado de trabalho e à produtividade do trabalho em algumas economias periféricas, bem como o acesso à serviços de saúde básica e políticas públicas para lidar situações adversas.

\section{Referências}

Alesina, A., Favero, C., e Giavazzi, F. (2020). Austerity: When it Works and when it Doesn't. Princeton University Press.

Alesina, A., Favero, C. A., e Giavazzi, F. (2018). What do we know about the effects of austerity? 108(5):524-30.

Anderson, D., Hunt, B., e Snudden, S. (2014). Fiscal consolidation in the euro area: How much pain can structural reforms ease? Journal of Policy Modeling, 36(5):785799.

Annicchiarico, B., Di Dio, F., e Felici, F. (2013). Structural reforms and the potential effects on the italian economy. Journal of Policy Modeling, 35(1):88-109.

Atkinson, A. B. (2015). Inequality: What can be done? Harvard University Press.

Bardaka, I., Bournakis, I., e Kaplanoglou, G. (2021). Total factor productivity (tfp) and fiscal consolidation: How harmful is austerity? Economic Modelling, 94:908-922.

Bassanini, A. e Duval, R. (2006). Employment patterns in oecd countries: Reassessing the role of policies and institutions. oecd economics department working papers no. 486. OECD Publishing (NJ1).

Bassanini, A. e Duval, R. (2009). Unemployment, institutions, and reform complementarities: re-assessing the aggregate evidence for oecd countries. Oxford Review of Economic Policy, 25(1):40-59.

Beatty, C. e Fothergill, S. (2013). Hitting the poorest places hardest: The local and regional impact of welfare reform. Sheffield Hallam University.

Boeri, T., Börsch-Supan, A., e Tabellini, G. (2002). Pension reforms and the opinions of european citizens. American Economic Review, 92(2):396-401.

Bouis, R., Causa, O., Demmou, L., Duval, R., e Zdzienicka, A. (2012). The short-term effects of structural reforms: an empirical analysis.

Brasil (2018). Teto de gastos: o gradual ajuste para o crescimento do país. Ministério da Economia.

Brasil (2019). Exportação e Importação geral. Base de dados 2017-2018. Ministério da Economia.

Brasil (2020). Relação Anual de Informações Sociais. Ministério da Economia. 
Cabrera, M., Lustig, N., e Morán, H. E. (2015). Fiscal policy, inequality, and the ethnic divide in guatemala. World Development, 76:263-279.

Caraveli, H. e Tsionas, E. G. (2012). Economic restructuring, crises and the regions: the political economy of regional inequalities in greece. London School of Economics and Political Science, Hellenic Observatory.

Cardoso, D., Souza, K., Ribeiro, L., e Cardoso, G. (2019). Fiscal policy and regional inequality in brazil. XXIV Encontro Regional de Economia-Artigos Selecionados.

Cardoso, G. S. (2019). Política fiscal e gasto público no brasil: impactos na renda das famílias e na atividade econômica. Universidade Federal de Minas Gerais.

Cardoso, G. S. (2022). A keyword on the footer: the Furtadian and the (re)current meaning of structural reforms. Brazilian Journal of Political Economy, 42(1):In press. DOI: 10.1590/0101-31572022-3262.

Carvalho, T. S., Domingues, E. P., e Horridge, J. M. (2017). Controlling deforestation in the brazilian amazon: Regional economic impacts and land-use change. Land Use Policy, 64:327-341.

Costa, F. L. d. (2008). Brasil: 200 anos de estado; 200 anos de administração pública; 200 anos de reformas. Revista de Administração Pública, 42(5):829-874.

Cruz, B. O. e Santos, I. R. S. (2011). Dinâmica do emprego industrial no brasil entre 1990 e 2009: uma visão regional da desindustrialização. Instituto de Pesquisa Econômica Aplicada (IPEA).

Dixon, P. e Rimmer, M. T. (2002). Dynamic general and equilibrium modelling for forecasting and policy: A practical guide and documentation of MONASH, volume 256. Elsevier.

Eslava, M., Haltiwanger, J., Kugler, A., e Kugler, M. (2004). The effects of structural reforms on productivity and profitability enhancing reallocation: evidence from colombia. Journal of development Economics, 75(2):333-371.

Fergusson, L., Molina, C., Robinson, J. A., e Vargas, J. F. (2017). The Long Shadow of the Past: Political Economy of Regional Inequality in Colombia. Documentos CEDE 015445, Universidad de los Andes - CEDE.

Ferreira, A. H. B. e Diniz, C. C. (1995). Convergência entre as rendas per capita estaduais no brasil. Brazilian Journal of Political Economy, 15(4).

Ferreira Filho, J. B. e Horridge, M. (2014). Ethanol expansion and indirect land use change in brazil. Land Use Policy, 36:595-604.

Galeano, E. e Feijó, C. (2013). A estagnação da produtividade do trabalho na indústria brasileira nos anos 1996-2007: análise nacional, regional e setorial. Nova Economia, 23(1):9-50. 
Giambiagi, F. e Horta, G. T. d. L. (2019). O teto do gasto público: mudar para preservar.

Giavazzi, F. e Pagano, M. (1990). Can severe fiscal contractions be expansionary? tales of two small european countries. NBER Macroeconomics Annual, 5:75-111.

Green, J. e Lavery, S. (2015). The regressive recovery: distribution, inequality and state power in Britain's post-crisis political economy. New Political Wconomy, 20(6):894-923.

Greer Murphy, A. (2017). Austerity in the united kingdom: the intersections of spatial and gendered inequalities. Area, 49(1):122-124.

Horridge, M. (2012). The term model and its database. Economic Modeling of Water, Springer.

IBGE (2011). Pesquisa de Orçamento Familiar 2008-2009. Instituto Brasileiro de Geografia e Estatística.

IBGE (2018). Sistema de Contas Nacionais: Brasil, referência 2015. Instituto Brasileiro de Geografia e Estatística.

Kodar, F. (2004). Pension (in) securities: Unpaid work, precarious employment and the canadian pension system. Atlantis, 28(2):93-102.

Mendes, P. S., Hermeto, A. M., Britto, G., et al. (2019). Reorganização espacial da indústria de transformação brasileira pós-2008: a evolução do emprego formal no território. Revista Brasileira de Estudos Regionais e Urbanos, 13(1):23-44.

Nicoletti, G. e Scarpetta, S. (2005). Product market reforms and employment in oecd countries.

Pearce, J. (2013). Commentary: financial crisis, austerity policies, and geographical inequalities in health. Environment and Planning A, 45(9):2030-45.

Peter, M. W., Horridge, J., Meagher, G., Naqvi, F., e Parmenter, B. R. (1996). The theoretical structure of monash-mrf. Centre of Policy Studies (COPS).

Ribeiro, L. C. D. S., Domingues, E. P., Perobelli, F. S., e Hewings, G. J. D. (2018). Structuring investment and regional inequalities in the brazilian northeast. Regional Studies, 52(5):727-739.

Rodrik, D. (2017). The elusive promise of structural reform. Political Economy Perspectives on the Greek Crisis. Springer.

Rubery, J. e Piasna, A. (2016). Labour market segmentation and the eu reform agenda: developing alternatives to the mainstream. ETUI Research Paper-Working paer.

Salto, F. S. e Barros, G. (2018). A importância da emenda constitucional nº 95/2016. Instituição Fiscal Independente, Nota técnica, (21). 
Shin, K.-Y. (2013). Economic crisis, neoliberal reforms, and the rise of precarious work in south korea. American Behavioral Scientist, 57(3):335-353.

Silva, F., Menezes Filho, N., e Komatsu, B. (2016). Evolução da produtividade no brasil: comparações internacionais. Policy Paper, 15(3):35-42.

Stone, R. (1954). Linear expenditure systems and demand analysis: an application to the pattern of british demand. The Economic Journal, 64(255):51 1-527.

Tupy, I. S. e Toyoshima, S. H. (2013). Impactos dos programas governamentais de transferência de renda sobre a economia do vale do jequitinhonha. Revista Econômica do Nordeste, 44(3):671-692.

Unni, J., Lalitha, N., e Rani, U. (2001). Economic reforms and productivity trends in indian manufacturing. Economic and Political Weekly, 12(1):3914-3922.

Veloso, F., Matos, S., e Coelho, B. (2015). Produtividade do trabalho no brasil: uma análise setorial. Ensaios IBRE de economia brasileira II, 1:75-107.

(ब) Ev 